\title{
AVALIAÇÃO FÍSICO-QUÍMICA E MICROBIOLÓGICA DAS ÁGUAS DA BACIA HIDROGRÁFICA DO RIO PARAÍSO JATAÍ-GO
}

\author{
Hudson Moraes Rocha ${ }^{1}$ \\ João Batista Pereira Cabral ${ }^{2}$ \\ Daiane Ferreira Batista ${ }^{3}$ \\ Leandro Gonçalves Oliveira ${ }^{4}$
}

Resumo: A atividade agropecuária é a principal consumidora e poluidora dos recursos hídricos, em que o desmatamento, a irrigação e os resíduos desta atividade são conduzidos à rede de drenagem. $O$ presente trabalho teve como objetivo analisar espacial e temporalmente as características físico-química e microbiológica das águas superficiais do rio Paraíso, e realizar o enquadramento do corpo d'água de acordo com a resolução CONAMA n ${ }^{\circ} 357 / 05$. As coletas de água no rio Paraíso foram realizadas em períodos distintos do ano: uma no mês de agosto (período seco) e outra em novembro (período chuvoso). Os parâmetros avaliados foram: temperatura da água, potencial hidrogeniônico, condutividade elétrica, salinidade, turbidez, oxigênio dissolvido, coliformes fecais, fósforo e nitrogênio. Os resultados dos coliformes fecais e fósforo apontam que os trechos amostrais de água nas áreas de agricultura apresentaram maior inadequabilidade de acordo com a Resolução CONAMA $n^{\circ} 357 / 05$, sendo o rio classificado como de classe III.

Palavras-chave: Atividade Agropecuária. Recurso hídrico. Meio ambiente.

\section{PHYSICAL, CHEMICAL AND MICROBIOLOGICAL EVALUATION OF THE PARAÍSO RIVER BASIN, JATAÍ, GOIÁS STATE}

Abstract: The agricultural activity is the main consumer and polluter of water resources, where deforestation, irrigation and waste from such activity are carried to the drainage network This study aimed to analyze spatially and temporally the physical, chemical and microbiological characteristics of surface waters of the Paraíso River, and classify the water body according to CONAMA Resolution 357/05. Water samples were taken in different periods, in August (dry season) and in November (rainy season). The parameters evaluated were: water temperature, $\mathrm{pH}$, electrical conductivity, salinity, turbidity, dissolved oxygen, fecal coliforms, phosphorus and nitrogen. The results of for fecal coliform and phosphorus showed that the stretches of samples water from located in the areas of agricultural had higher unsuitability according to CONAMA Resolution 357/05, classifying the river as Class III.

Keywords: Agricultural activity. Water resource. Environment.

\footnotetext{
${ }^{1}$ Universidade Federal de Goiás, Goiânia, Goiás, Brasil, sauhudson@gmail.com, https://orcid.org/0000-00018431-0628

2 Universidade Federal de Goiás, Jataí, Goiás, Brasil, jbcabral2000@yahoo.com.br, https://orcid.org/0000-00032046-5975

${ }^{3}$ Universidade Federal de Goiás - Jataí - Goiás - Brasil, daiane-fb@hotmail.com, https://orcid.org/0000-00018548-4021

${ }^{4}$ Universidade Federal de Goiás, Goiânia, Goiás, Brasil, legospy@gmail.com, https://orcid.org/0000-0002-6570$643 X$
} 


\section{EVALUACIÓN FÍSICO-QUÍMICA Y MICROBIOLÓGICA DE LAS AGUAS DE LA CUENCA HIDROGRÁFICA DEL RÍO PARAÍSO JATAÍ-GO}

Resumen: La actividad agropecuaria es la principal consumidora y contaminante de los recursos hídricos. La deforestación, la irrigación y otras actividades agropecuarias producen residuos que son conducidos a la red de drenaje. El presente trabajo tuvo como objetivo analizar espacial y temporalmente las características físico-químicas y microbiológicas de las aguas superficiales del río Paraíso, y realizar la caracterización del cuerpo de agua de acuerdo con la resolución CONAMA $n^{\circ}$ 357/05. Los muestreos del agua en el río Paraíso se realizaron en períodos distintos del año: una en el mes de agosto (período seco) y otra en noviembre (período lluvioso). Los parámetros evaluados fueron: temperatura del agua, potencial hidrogeniónico, conductividad eléctrica, salinidad, turbidez, oxígeno disuelto, coliformes fecales, fósforo y nitrógeno. Los resultados de los coliformes fecales y fósforo en los extractos colectados de las áreas de agricultura indican que las aguas no son adecuadas según la Resolución CONAMA n 357/05, siendo el río clasificado como de clase III.

Palaras clave: Actividad agropecuária. Recurso hídrico. Medio ambiente.

\section{Introdução}

Água é um dos elementos mais importantes para a manutenção da vida terrestre, pois desempenha diversas funções indispensáveis à vida, como a regulação celular dos seres vivos (YAMAGUCH et al., 2013). A fotossíntese é um dos principais mecanismos que auxiliaram na evolução vegetal e depende da água para a liberação de oxigênio (HAVEN et al., 2001).

A qualidade das águas superficiais de consumo humano pode ser afetada por processos naturais de ciclos biogeoquímicos, já que, com as chuvas, por meio do intemperismo das rochas, contendo fosfato por exemplo, são carregados para os cursos d'água. No meio rural, a qualidade da água está relacionada com a transformação do ambiente equilibrado pela forma de ocupação do solo, sendo que, nas áreas de agropecuária, há o uso indiscriminado de defensivos e fertilizantes agrícolas e a falta de tratamento dos dejetos animais e humanos, que acabam alterando os processos naturais do ecossistema aquático (MARTINS, 2009).

A agricultura é a principal consumidora e poluidora dos recursos hídricos, em que a salinidade e a concentração de nitrato são um dos principais indicadores (ONGLEY, 2001; BROWN et al., 2000 apud BRITO et al., 2005). As consequências dessa poluição decorrente, principalmente, do aumento dos nutrientes (por exemplo, nitrogênio e fósforo) devido à remoção do solo pelas chuvas nas áreas agrícolas, provocam, entre outros, o crescimento de plantas aquáticas e, consequentemente, o 
acúmulo de matéria orgânica nos corpos da água, causando prejuízos ao ambiente e à saúde humana (RESENDE, 2002).

Conforme Carvalho et al. (2000), a formação de pastagens para a criação de animais agropecuários diminui a diversidade vegetal. $\mathrm{O}$ pisoteio dos animais e a manutenção dos pastos propicia o empobrecimento em nutrientes e a compactação do solo, o que facilita a entrada do material edáfico carregado de matéria orgânica, inorgânica e até compostos químicos no sistema aquático, o que provoca alterações químicas e ecológicas na fauna e flora aquática.

Assim, a água, devido às suas propriedades de solvente e à sua capacidade de transportar partículas, se inter-relaciona com as propriedades físico-geográficas (bacia hidrográfica, geologia, geomorfologia, uso e ocupação e rede de drenagem), o que confere características próprias a cada ecossistema. Dessa forma, pode-se dizer que a qualidade da água é determinada em função da bacia hidrográfica (ROCHA et al., 2014).

O monitoramento ambiental das características físico-químicas da água permite identificar e quantificar os elementos iônicos e, a partir das análises, os teores encontrados podem ser comparados com os padrões de qualidade da água existentes. Associando os efeitos de suas propriedades em relação às causas ambientais, pode-se sugerir ou não outros tipos de investigação para se descobrir o nível de degradação da bacia hidrográfica, ou propor ações de mitigação para esses efeitos.

Neste trabalho, realizou-se uma análise espacial e temporal das características físico-química e microbiológica das águas superficiais do rio Paraíso, no município de Jataí (GO). Como o rio Paraíso está inserido em área agrícola, foram identificados os principais fatores ambientais que interferem na qualidade da água sob influência da atividade agropecuária e, posteriormente, foi feita a classificação e o enquadramento dos trechos amostrais de água conforme as diretrizes ambientais da Resolução CONAMA n $357 / 05$ (BRASIL, 2005).

\section{Descrição da área e das bacias de amostragem}

A bacia do rio Paraíso está localizada no município de Jataí, ao Sudoeste do Estado de Goiás, delimitada entre as coordenadas UTM $E=425000 \mathrm{~m}, E=450000 \mathrm{~m}$ e $\mathrm{N}=800300 \mathrm{~m}, \mathrm{~N}=803800 \mathrm{~m}$, mapeados pelas folhas SE-22-V-D e SE-22-Y-B (IBGE, 1978) (Figura 1). 
Figura 1. Localização dos pontos de amostragem na bacia do rio Paraíso Jataí-GO.

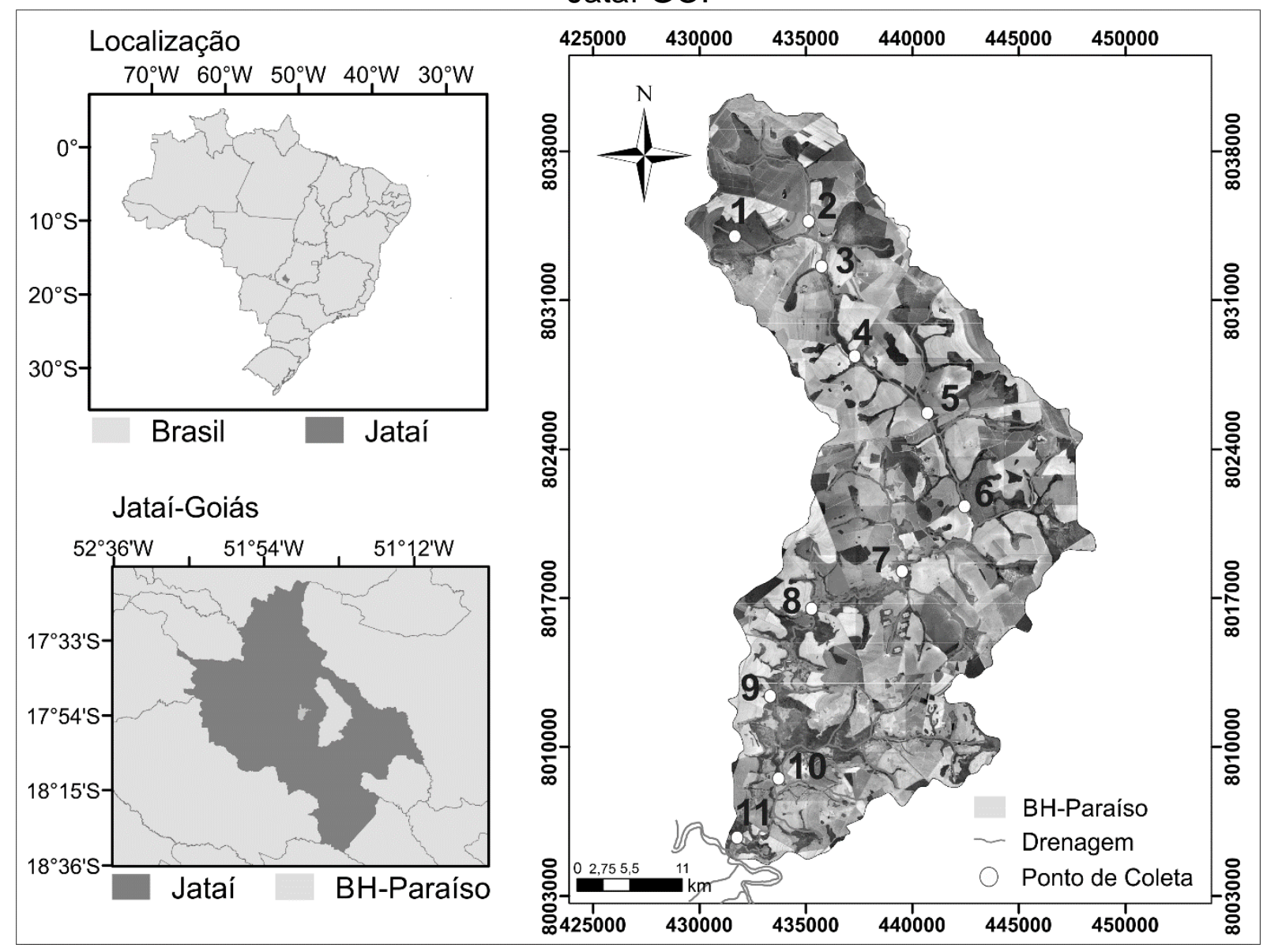

Fonte: Sistema Estadual de Estatística e de Informações Geográficas de GoiásSIEG, 2014. Org. dos autores.

O rio Paraíso é tributário do rio Claro e afluente do rio Paranaíba, pertencentes a Bacia hidrográfica do Rio Paraná. O rio Paraíso escoa sobre o substrato da Formação Serra Geral constituído de basaltos do Cretáceo Inferior do, Grupo São Bento e Arenitos da Formação Vale do Rio do Peixe, Grupo Bauru, depositadas no Cretáceo Superior, e ainda Cobertura Arenosa Indiferenciada sedimentos arenosos do Pleistoceno. A bacia do rio Paraíso recobre uma superfície de $362 \mathrm{~km}^{2}$, sendo que a área desmatada para o uso de pastagem e agricultura é de $87,7 \%$, enquanto a vegetação destinada à reserva legal e proteção dos cursos d'água é de $12,4 \%$, e $0,1 \%$ de corpo d'água (SIEG, 2014). 


\section{Procedimento metodológico}

As coletas de água foram realizadas sazonalmente, com uma amostragem no dia 28 de agosto de 2014 (período seco) e outra no dia 11 de novembro de 2014 (período chuvoso) em 11 pontos distintos do rio (Tabela 1 e Figura 1). Os estabelecimentos dos pontos de amostragens foram a $5 \mathrm{~km}$ de distância de um ponto para o outro no rio Paraíso (montante à jusante) de modo que toda a área da bacia hidrográfica fosse abrangida para se verificar a influência do uso e ocupação do solo na qualidade da água.

Tabela 1. Descrição dos pontos de amostragem do rio Paraíso.

\begin{tabular}{|r|r|r|r|l|}
\hline Pt. & Largura & Profundidade & \multicolumn{1}{|c|}{$\begin{array}{c}\text { Vazão Total } \\
(\mathbf{m} 3 / \mathbf{s})\end{array}$} & \multicolumn{1}{|c|}{ Uso do Solo } \\
\hline $\mathbf{1}$ & 1,40 & 0,23 & 0,08 & Área de vegetação preservada \\
\hline $\mathbf{2}$ & 1,63 & 0,55 & 0,22 & Área de influência agrícola \\
\hline $\mathbf{3}$ & - & - & - & Rio represado de influência agrícola \\
\hline $\mathbf{4}$ & 5,28 & 0,83 & 1,29 & Área de influência agrícola - vegetação \\
\hline $\mathbf{5}$ & 5,69 & 0,52 & 1,34 & Área de influência agrícola \\
\hline $\mathbf{6}$ & 6,12 & 0,89 & 1,85 & Área de influência de pecuária \\
\hline $\mathbf{7}$ & 9,26 & 0,50 & 1,91 & Área de influência agrícola - vegetação \\
\hline $\mathbf{8}$ & 9,73 & 1,38 & 2,40 & Área de influência agrícola - vegetação \\
\hline $\mathbf{9}$ & 8,79 & 1,48 & 2,58 & Área de influência agrícola \\
\hline $\mathbf{1 0}$ & 9,77 & 1,27 & 2,93 & Área de influência de pecuária \\
\hline $\mathbf{1 1}$ & 8,05 & 1,43 & 2,85 & Área de influência agrícola - pecuária \\
\hline
\end{tabular}

Fonte: Dados da pesquisa (2014). Org. dos autores.

Os parâmetros físicos e químicos das águas avaliados foram: temperatura da água $\left({ }^{\circ} \mathrm{C}\right)$, potencial hidrogeniônico $(\mathrm{pH})$, condutividade elétrica $(\mathrm{CE})$, cloreto de sódio ( $\mathrm{NaCl})$, oxigênio dissolvido (OD), determinados com o uso do aparelho Oakton, modelo PCD650, e a turbidez (TURB) pelo aparelho do modelo HI 93703 (Hanna). A avaliação microbiológica foi feita pela contagem de coliformes termotolerantes totais e coliformes termotolerantes (CT) semeados em meio de cultura ágar, segundo os critérios de assepsia. Para avaliação fósforo total (PT), utilizou-se o método de vanadomolíbdico fotocolorímetro e para a medida da concentração de nitrogênio total (NT) foi utilizada a técnica do persulfato/Brucina, o 
uso do equipamento multíparâmetro de bancada da AT100 Alfakit. Os procedimentos de análise da água seguiram as técnicas descritas do Standard Methods for the Examination of Water and Wastewater (APHA, 1998).

\section{Análise de regressão linear}

Através das análises dos dados, os resultados obtidos foram tabulados e submetidos a tratamento estatístico para elaboração de tabelas e gráficos. A análise de regressão linear foi aplicada para indicar o grau de associação entre as variáveis físicas, químicas da água e microbiológica, com dados nas escalas de "intervalos ou de razões", podendo a correlação variar de +1 a -1 , por meio do coeficiente de correlação linear. Visando discutir as medidas deste coeficiente de correlação linear foram estabelecidos intervalos de correlação (variando de $+1 \mathrm{a}-1$ ) (Tabela 2), adaptado do trabalho de Santos (2007).

Tabela 2. Intervalos do coeficiente de correlação linear.

\begin{tabular}{cc}
\hline Coeficiente de correlação & Correlação \\
\hline$r=1$ & Perfeita positiva \\
$0,7 \leq r<1$ & Forte positiva \\
$0,4 \leq r<0,7$ & Moderada positiva \\
$0,1 \leq r<0,4$ & Fraca positiva \\
$0<r<0,1$ & Ínfima positiva \\
0 & Nula \\
$-0,1<r<0$ & Ínfima negativa \\
$-0,4<r \leq-0,1$ & Fraca negativa \\
$-0,7<r \leq-0,4$ & Moderada negativa \\
$-1<r \leq-0,7$ & Forte negativa \\
$r=-1$ & Perfeita negativa \\
\hline
\end{tabular}

Fonte: Adaptado de Santos, 2007.

\section{Resultados e Discussão}

$\mathrm{Na}$ Figura 2, a temperatura da água, no período seco, teve o menor valor de $19,3^{\circ} \mathrm{C}$ no ponto 10 , área de influência de pecuária, e o maior valor $22,6^{\circ} \mathrm{C}$ foi detectado no ponto 3 , trecho do rio represado para atender a uma fazenda agroindustrial. Observou-se, no período chuvoso, o menor valor de temperatura da água, de $20,2^{\circ} \mathrm{C}$, detectado no ponto 9 , área de influência agrícola, e o maior valor de $26,0^{\circ} \mathrm{C}$ no ponto 5 , trecho amostral localizado próximo à rodovia BR-060, sob 
influência agrícola com muitas sedes de fazendas ao redor do trecho amostral, com fluxo de efluentes domésticos e de animais. Verificou-se, ainda que, as leituras amostradas no período de estiagem tiveram os menores valores em relação aos dados do período úmido, o que pode ser explicado devido à maior incidência de radiação solar nos corpos da água, pois o anticiclone polar sobre a região centrooeste provoca a queda da temperatura do ar e, consequentemente, dos corpos d'água (ROCHA et al., 2014; LIMA e MARIANO, 2014).

Figura 2. Análise da temperatura $\left({ }^{\circ} \mathrm{C}\right)$ da água do rio Paraíso.

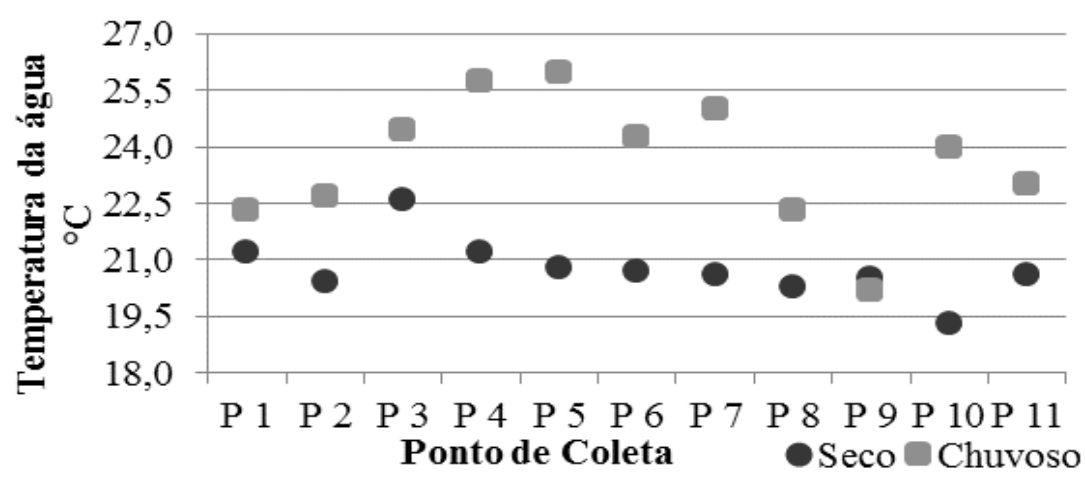

Fonte: Dados da pesquisa (2014). Org. dos autores.

O desmatamento para o uso agrícola nas áreas de influência dos pontos 3, 4 e 5 do rio Paraíso é outro fator a ser levado em consideração para elevação da temperatura da água. Silva (2000), encontrou valores de temperatura da água variando de 14,5 a $28,8^{\circ} \mathrm{C}$ no inverno, mostrando que os valores de temperatura são fortemente associados com características do período do ano e a preservação da vegetação (temperaturas menores).

Observa-se na Figura 3 que, no período seco, o menor valor de potencial hidrogeniônico $(\mathrm{pH})$ foi de 5,9 detectado na nascente do rio Paraíso (ponto 1), área de mata de galeria de vegetação preservada, sendo essa fisionomia de característica perenifólia, na qual não apresenta queda de folhas na estação seca (SANO, ALMEIDA e RIBEIRO, 2008), enquanto que o maior valor de $\mathrm{pH}$ de 7,2 foi encontrado no ponto 9, área de intensa atividade agrícola, principalmente pelo plantio de soja e milho. No período chuvoso, o menor valor de $\mathrm{pH}$ foi de 5,6 e ocorreu no ponto 1 e o maior valor de $\mathrm{pH}$ foi de 7,1 no ponto 11 . No entanto, as medidas de $\mathrm{pH}$ do ponto 1 estão abaixo do valor de $\mathrm{pH}$ de referência estabelecido pela Resolução CONAMA n 357/05 (BRASIL, 2005) para as águas de classe I destinadas ao consumo humano. $\mathrm{O}$ valor de $\mathrm{pH}$ para as águas naturais do Bioma 
Cerrado se caracteriza por serem muito ácidos devido às propriedades do solo, ao qual existe a necessidade de adição de calcário para correção, o que faz com que aumente a concentração de íons $\mathrm{Ca}^{2+}$ nas águas.

Figura 3. Análise do potencial hidrogeniônico da água do rio Paraíso.

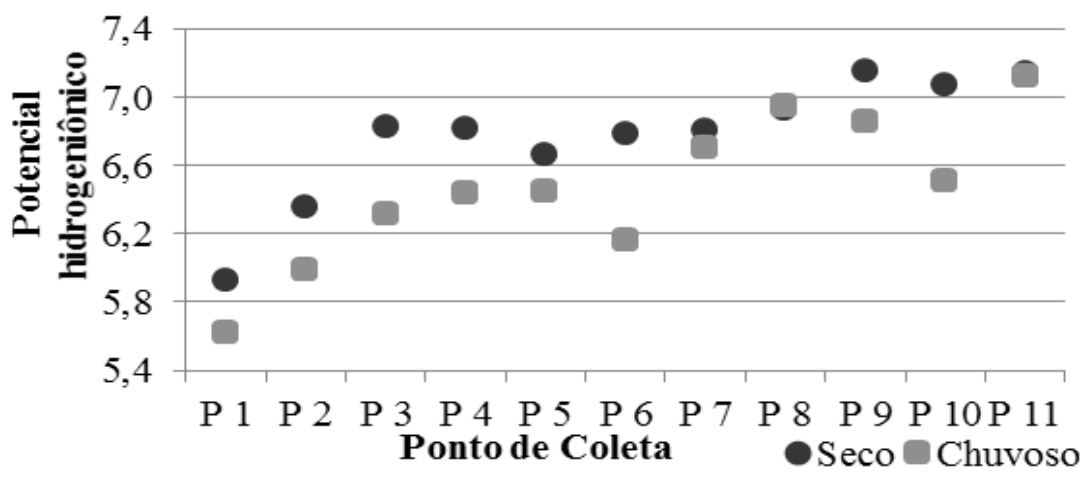

Fonte: Dados da pesquisa (2014). Org. dos autores.

De acordo com a Figura 4, no período seco, o menor valor da condutividade elétrica (CE) foi de $3,7 \mu \mathrm{S} / \mathrm{cm}$, registrada no ponto 1 , nascente do rio Paraíso, e o maior valor da CE de 19,6 $\mu \mathrm{S} / \mathrm{cm}$ foi detectado no ponto 11 à jusante do rio Paraíso. A CE, no período chuvoso, o menor valor de CE foi de $4,3 \mu \mathrm{S} / \mathrm{cm}$ ocorrendo no ponto 1 e o maior valor da CE de $22,7 \mu \mathrm{S} / \mathrm{cm}$ no ponto 11 . A CE teve valores inferiores a $50 \mu \mathrm{S} / \mathrm{cm}$ considerados baixos pela literatura (COLUNA, 2007; ROCHA et al., 2014).

Figura 4. Análise da condutividade elétrica $(\mu \mathrm{S} / \mathrm{cm})$ da água do rio Paraíso.

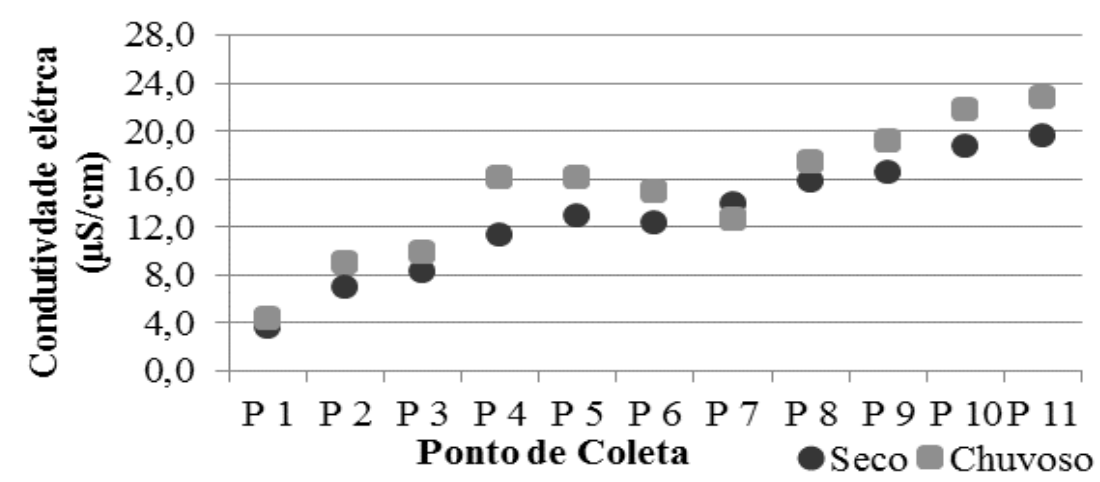

Fonte: Dados da pesquisa (2014). Org. dos autores.

Nos pontos localizados à nascente do rio Paraíso, a CE sofre a interferência do substrato da formação geológica da Cobertura Arenosa Indiferenciada e dos solos pertencentes à classe Cambissolo que são pouco desenvolvidos e constituídos 
por rochas resistentes ao intemperismo, e os valores médios estão associados à Formação Vale do Rio do Peixe, de solos da classe dos Latossolos ricos em carbonatos de cálcio $\left(\mathrm{CaCO}_{3}\right)$ ou carbonato de magnésio $\left(\mathrm{MgCO}_{3}\right)$, o que aumenta a condutividade após a dissolução no sistema aquático (ZILLMER et al., 2007).

Os resultados das medidas de cloreto de sódio $(\mathrm{NaCl})$ são apresentados na Figura 5, e estão em concordância com os resultados obtidos de CE, que depende da concentração de íons dissolvidos em solução aquosa. Mesmo considerando o limite máximo $\mathrm{NaCl}$, que, segundo a Resolução n 357/05 do CONAMA (BRASIL, 2005), em que sua concentração em águas doces do tipo I destinadas ao consumo devem ser até $250 \mathrm{mg} / \mathrm{L}$, o ponto 11 do rio Paraíso teve valores inferiores ao estipulado pela resolução. Verificou-se ainda que houve o aumento gradativo dos valores de $\mathrm{NaCl}$ dos pontos situados da nascente à foz do rio Paraíso, indicando a existência de maior dissolução de sais das rochas nos trechos de maior vazão de água. $\mathrm{E}$, na estação chuvosa, o $\mathrm{NaCl}$ teve os maiores valores, o que sugere a maior entrada de nutrientes agrícolas pelo escoamento superficial.

Figura 5. Análise cloreto de sódio (mg/L) da água do rio Paraíso.

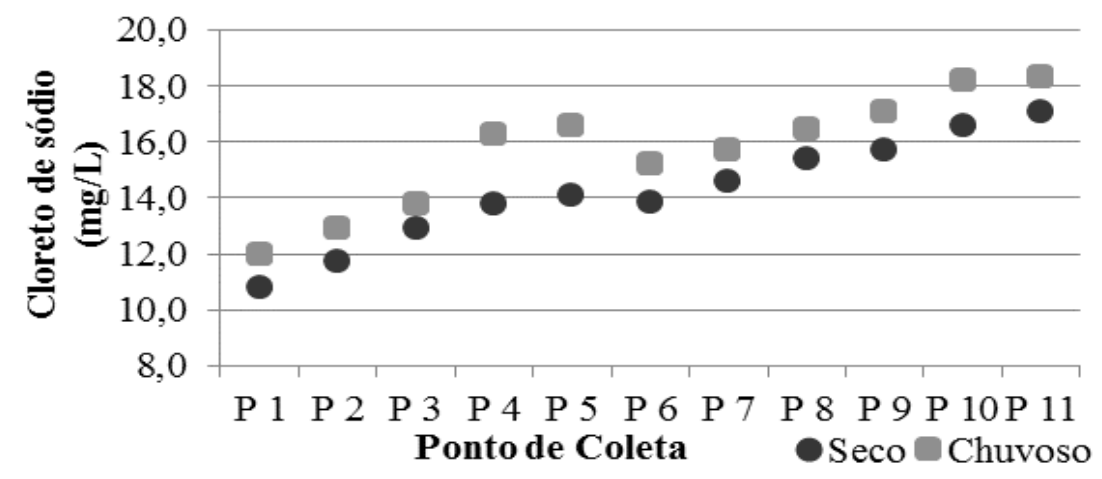

Fonte: Dados da pesquisa (2014). Org. dos autores.

Nota-se que, na Figura 6, no período seco, o menor valor de turbidez encontrado foi de 2,1 NTU no ponto 1, trecho do rio de difícil acesso e com a vegetação nativa bem preservada, e o maior valor de 10,4 NTU no ponto 5, próximo à rodovia BR-060, com muitas sedes de fazenda e lançamento de efluentes domésticos e animais no leito do rio Paraíso. A turbidez no período chuvoso teve o menor valor de 10,7 no ponto 1 , e o maior valor de 35,4 no ponto 6 , caracterizado pela intensa atividade pecuarista, que associado com a fragilidade dos solos arenosos e as fortes chuvas, observa-se o aumento da quantidade de sedimentos carreados para a rede de drenagem. Assim, os valores registrados de turbidez na estação seca, no rio Paraíso, foram menores do que na estação chuvosa, o que 
pode ser explicado, devido ao fato de não haver o escoamento superficial no período seco que cause a remoção das partículas de solo para rede de drenagem.

Figura 6. Análise da turbidez (NTU) da água do rio Paraíso.

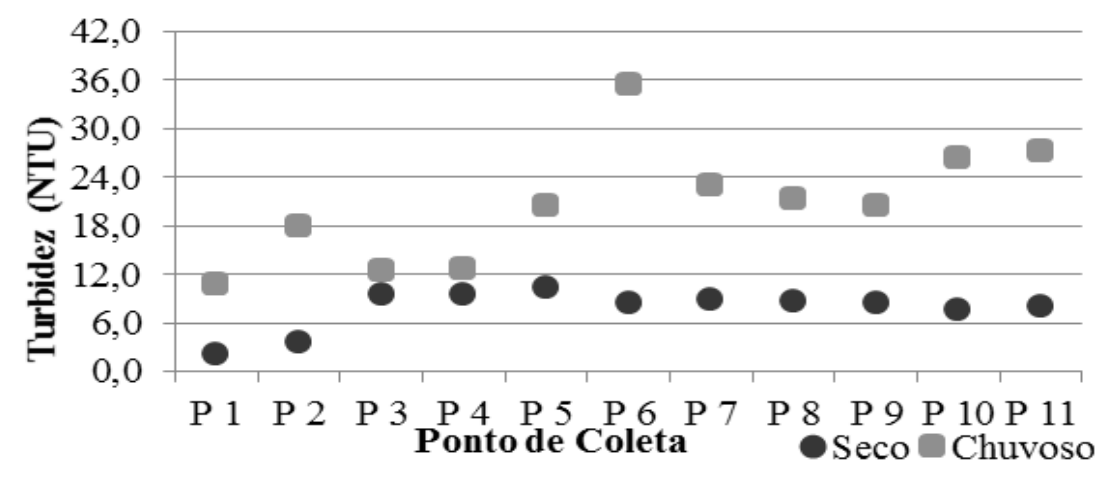

Fonte: Dados da pesquisa (2014). Org. dos autores.

Segundo Martins (2009), o lançamento de resíduos agrícolas nos cursos da água aumenta a carga orgânica e inorgânica, elevando a turbidez. Apesar disso, os valores de turbidez no rio Paraíso estão dentro dos padrões propostos pela resolução CONAMA no 357/05 (BRASIL, 2005) que é, no máximo, 40 NTU para os corpos de água doce do tipo I.

$\mathrm{Na}$ Figura 7, apresentamos os dados de coliformes termotolerantes (CT). Verifica-se que, no período seco, o menor valor de CT foi de $0,00 \mathrm{NMP} / 100 \mathrm{~mL}$ registrado no ponto 1 , em área de preservação (nascente do rio Paraíso), caracterizado por água límpida e baixo teor de nutrientes e, enquanto o maior valor de $6.073,0 \mathrm{NMP} / 100 \mathrm{~mL}$ registrado no ponto 5, próximo à rodovia BR-060, área sob influência agrícola com muitas sedes de fazendas ao redor do trecho amostral, o que sugere a criação de animais domésticos (gado leiteiro, porco, ave, cachorro, etc.), uma vez que os CT fazem parte da flora intestinal de homeotermos e causam aumento desses índices, se lançados na água (MARTINS, 2009).

Conforme a Resolução CONAMA n $357 / 05$ (BRASIL, 2005), os valores de CT para as águas classificadas como tipo I, não deve exceder um limite de 200NMP/100mL. Diante disso, verifica-se que, no período seco, existe uma elevação da contaminação por CT na maioria dos pontos, exceto nos pontos 1 e 2, podendo 0 rio Paraíso ser enquadrado na classe tipo III da Resolução, provavelmente devido à menor diluição dos resíduos no período seco em comparação ao período chuvoso. 
Figura 7. Análise dos coliformes termotolerantes NMP/100mL da água do rio Paraíso.

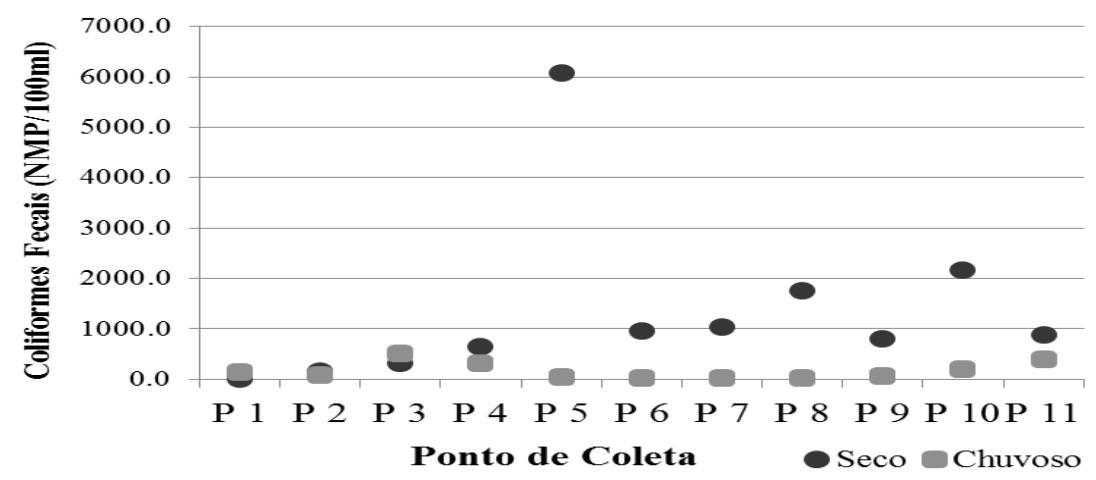

Fonte: Dados da pesquisa (2014). Org. dos autores.

Na Figura 8, observa-se que, no período seco, a menor concentração de oxigênio dissolvido (OD) é de $6,2 \mathrm{mg} / \mathrm{L}$ no ponto 3 , o que era esperado devido à redução no turbilhamento da água por estar represada e, a maior concentração de OD de $7,9 \mathrm{mg} / \mathrm{L}$ foi registrado no ponto 8 , possivelmente devido aos valores de vazão superiores, encontrados nesse ponto da nascente. No período chuvoso, registrou-se o menor valor da concentração de OD, de $6,6 \mathrm{mg} / \mathrm{L}$ no ponto 4 , área agrícola - vegetação, e o maior valor de $7,7 \mathrm{mg} / \mathrm{L}$ foi registrado no ponto 11 , área de agricultura-pecuária.

Figura 8. Análise do oxigênio dissolvido (mg/L O2) da água do rio Paraíso.

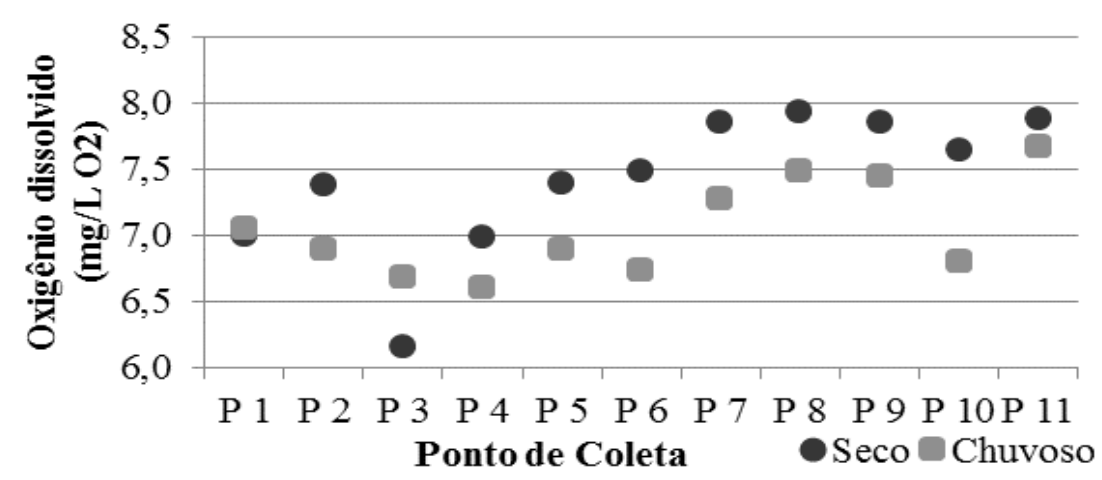

Fonte: Dados da pesquisa (2014). Org. dos autores.

Pode-se observar que, nos pontos 6 e 10, de uso para pecuária, no período chuvoso, obtiveram-se os menores valores de $\mathrm{OD}$ em relação aos outros pontos. Geralmente, em área de pecuária, o solo é compactado e a vegetação nativa do rio é retirada para que os animais (principalmente gado) possam beber água, e isso favorece o escoamento e a entrada de matéria orgânica nos rios. A decomposição da matéria orgânica faz com que aumentem as reações de oxidação química e 
bioquímica na depuração, diminuindo o OD (MARTINS, 2009). No estudo realizado por Nascimento et al. (2012), no rio Água Fria, o OD variou de $8,1 \mathrm{mg} / \mathrm{L}$ no ponto 1 (montante) a 3,8 mg/L no ponto 3 (jusante). Os autores concluem que a diminuição do OD no percurso do rio Água Fria é devida ao aumento da decomposição da matéria orgânica, um processo que consome oxigênio para depurar as substâncias orgânicas. De acordo a resolução CONAMA n $357 / 05$, em cursos d'água classe I, a concentração de OD não deve ser inferior a $6,0 \mathrm{mg} / \mathrm{L}$, portanto os dados estão em conformidade com a Resolução.

$\mathrm{Na}$ análise de fósforo total (PT), observa-se na Figura 9, no período seco, que o menor valor de $0,00 \mathrm{mg} / \mathrm{L}$ ocorreu nos pontos $1 ; 2 ; 5 ; 6 ; 7 ; 9 ; 10$ e o maior valor de $0,07 \mathrm{mg} / \mathrm{L}$ foi registrado no ponto 8 , com o uso agrícola do solo. No período chuvoso, o menor valor de 0,03 , registrado no ponto 2 , e o maior valor de $0,85 \mathrm{mg} / \mathrm{L}$ foi registrado no ponto 7 , área de influência de agricultura. As altas concentrações de PT no período chuvoso, no rio Paraíso, podem estar relacionadas à aplicação de fertilizantes fosfatados das áreas agrícolas, comuns para a correção do solo e, assim, eleva as concentrações de PT. Conforme a Resolução CONAMA n $357 / 05$, o PT classificado como tipo I, o nível máximo permitido é de $0,1 \mathrm{mg} / \mathrm{L}$. Assim, constata-se que, no período chuvoso, apenas os pontos 1 e 2, localizados à nascente do rio Paraíso, estão inseridos na classe I. Os demais pontos do rio Paraíso estão enquadrados na classe III conforme a Resolução CONAMA n 357/05 (BRASIL, 2005).

Figura 9. Análise do fósforo $(\mathrm{mg} / \mathrm{L} \mathrm{P})$ da água do rio Paraíso.

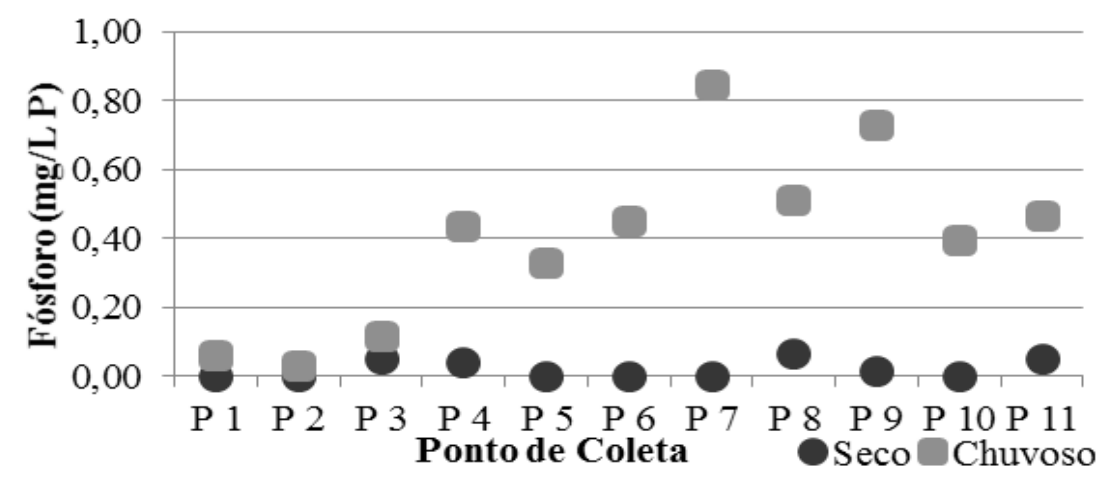

Fonte: Dados da pesquisa (2014). Org. dos autores.

Os valores de nitrogênio total (NT), no período seco, demonstrados na Figura 10 , foram de $0,00 \mathrm{mg} / \mathrm{L}$ para todos os pontos da bacia. Observando-se, no período chuvoso, o menor valor NT de $0,00 \mathrm{mg} / \mathrm{L}$ foi registrado nos pontos $1,3,4,5,7,9 \mathrm{e}$ 
10 e o maior valor de $0,39 \mathrm{mg} / \mathrm{L}$ foi registrado no ponto 8 , área de influência agrícola. Diante disso, a Resolução CONAMA n 357/05 (BRASIL,2005), estabelece que o NT classificado como tipo I, deve apresentar o valor $3,7 \mathrm{mg} / \mathrm{L} \mathrm{N}$, para $\mathrm{pH} \leq 7,5 \mathrm{e}$, portanto, em ambas as análises, espacial e temporal, para o rio Paraíso tiveram valores inferiores do estabelecido pela legislação vigente.

Figura 10. Análise nitrogênio amoniacal total $(\mathrm{mg} / \mathrm{L} \mathrm{N})$ da água do rio Paraíso.

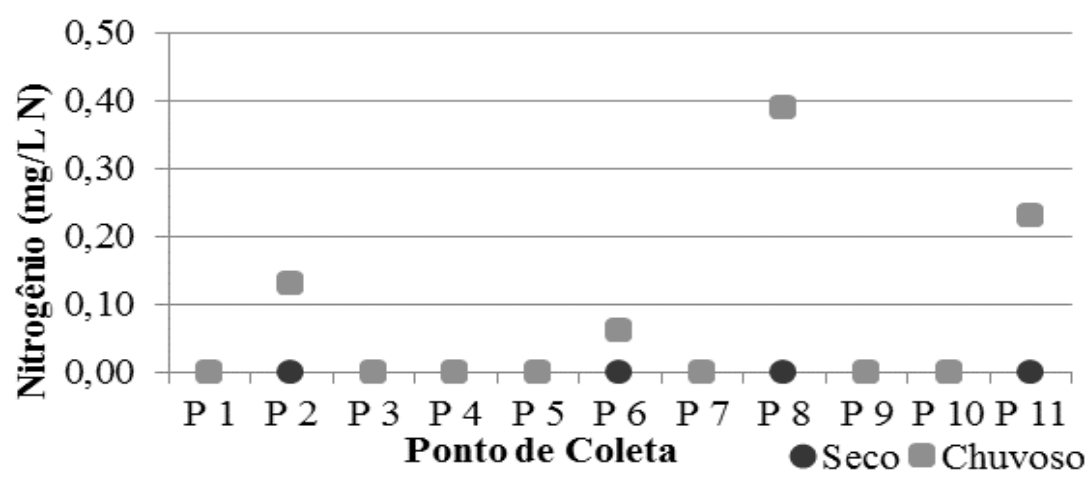

Fonte: Dados da pesquisa (2014). Org. dos autores.

\section{Análise da correlação de Pearson}

A utilização da análise de Correlação de Pearson permitiu identificar a relação entre os parâmetros físico-químicos da água, e estabelecer as melhores variáveis de correlação. $\mathrm{Na}$ análise entre os períodos seco e chuvoso somente foram discutidas as variáveis que tiveram relação com correlações moderadas (positiva ou negativa) dos parâmetros físico-químicas e microbiológicas da água.

Analisando as correlações (Tabela 3 e Figura 11-a), no período seco, verificamos correlação moderada negativa entre a temperatura da água e CE com o valor de $r=-0,586$ e no período chuvoso uma correlação de ínfima negativa com o valor de $r=-0,027$. Percebe-se, ainda, na Figura11-a, que o coeficiente que melhor se ajustou ao diagrama de dispersão foi o do período seco de 2014 , com $34 \%$ dos dados ajustado linearmente. Os pontos 1 e 2 situados à nascente do rio Paraíso obtiveram as medidas mais dispersas da linha central, o que indica uma baixa temperatura e pouca entrada de íons no ambiente aquático, quando comparada aos pontos de predominância da atividade agropecuária.

Tabela 3. Correlações de Pearson entre as variáveis físicas e químicas da água do rio Paraíso-Goiás. Período de estudo de agosto e novembro de 2014. 


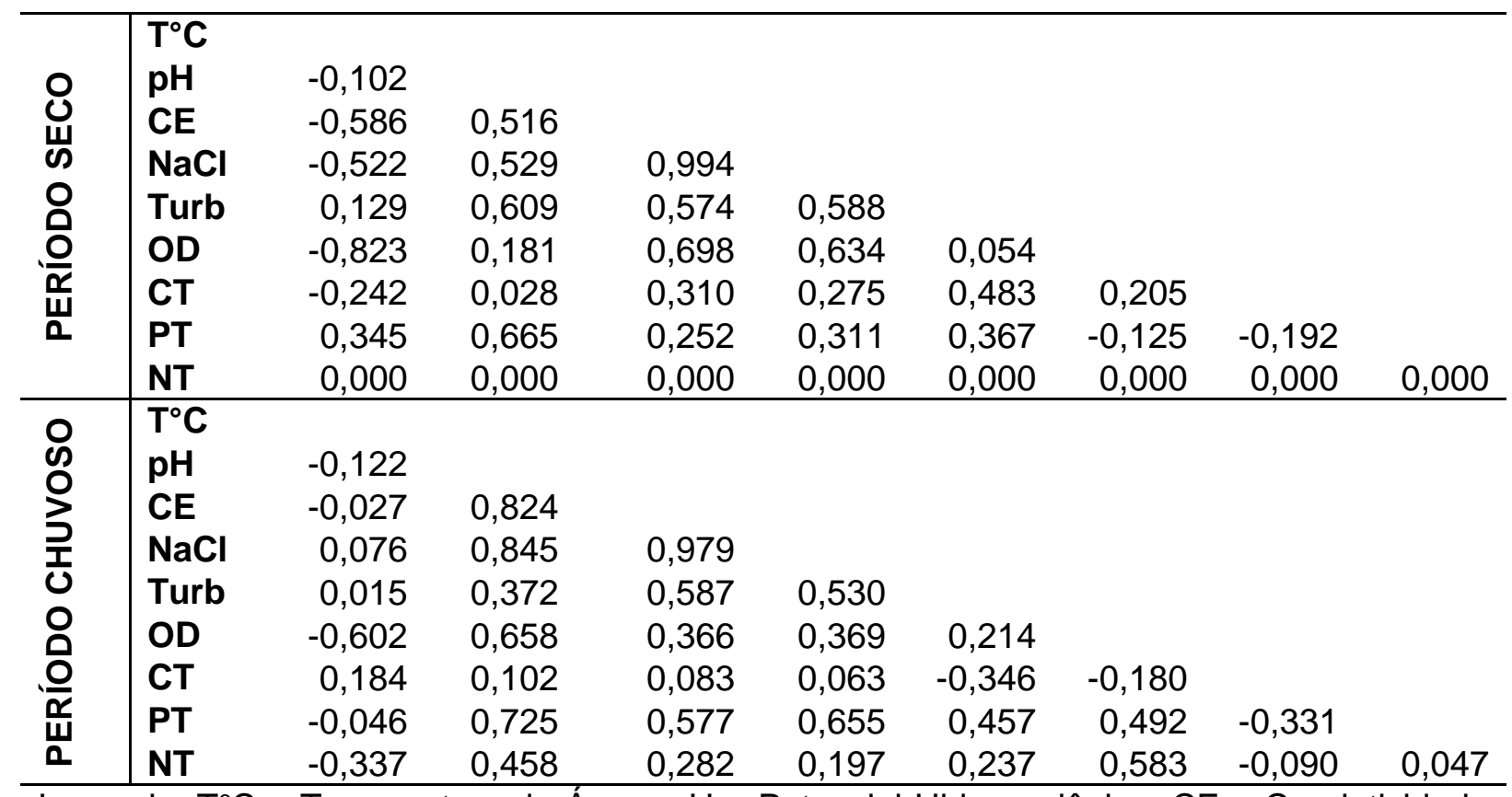

Legenda: $\mathrm{T}^{\circ} \mathrm{C}$ - Temperatura da Água; $\mathrm{pH}$ - Potencial Hidrogeniônico; CE - Condutividade Elétrica; $\mathrm{NaCl}$ - Cloreto de Sódio; Turb - Turbidez; OD - Oxigênio Dissolvido; CT Coliformes termotolerantes; DBO - Demanda Bioquímica de Oxigênio; PT - Fósforo Total; NT- Nitrogênio Total. Valor crítico do coeficiente de correlação de 0,602 significância para o limite de confiança de $\alpha=0,05$.

Fonte: Dados da pesquisa (2014). Org. dos autores.

De acordo com a Tabela 3, no período seco, encontramos uma correlação moderada negativa entre temperatura da água e o $\mathrm{NaCl}(r=-0,522)$ e uma correlação ínfima positiva $(r=0,076)$ no período chuvoso. O coeficiente linear da temperatura da água e o $\mathrm{NaCl}$ (Figura 11-b), no período seco, explicou 27\% dos dados ajustados à linha de tendência, demonstrando que a temperatura da água influência nos processos geoquímicos na disponibilidade de íons na água.

Figura 11. Análise de correlação de Pearson do parâmetro de temperatura $\left({ }^{\circ} \mathrm{C}\right)$ da água com a $\mathrm{CE}$ (a) e o $\mathrm{NaCl}$ (b) para o rio Paraíso Jataí-GO.

a)

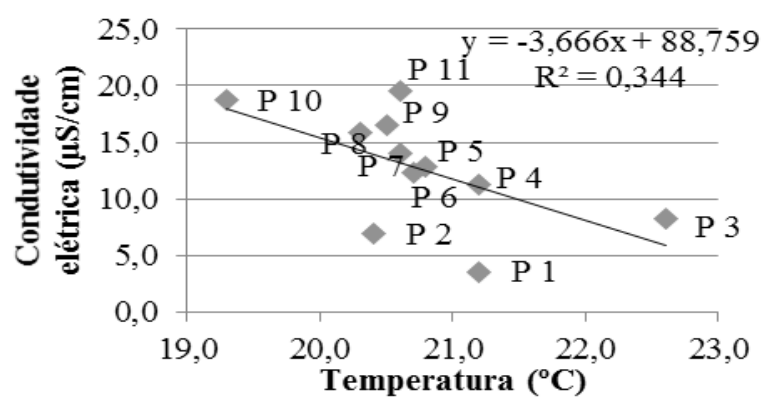

b)

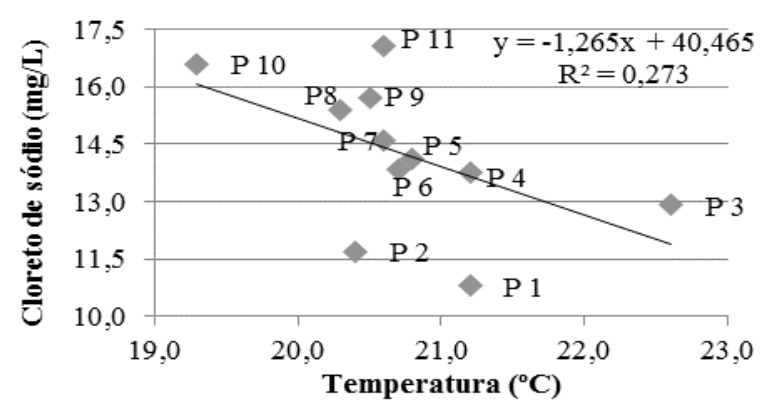

Fonte: Dados da pesquisa (2014). Org. dos autores. 
O coeficiente de determinação linear entre a temperatura da água e OD, no período seco, indicou $68 \%$ dos dados ajustados à linha do diagrama de dispersão. 0 delineamento da linha indica que, quanto menor o valor de temperatura, maior é o valor de OD na água (Tabela 3 e Figura12-a). Carvalho et al. (2000) afirmam que, a temperatura da água e o OD estão relacionados, efeito este constatado no Ribeirão Feijão. Entretanto, não observaram uma correlação entre temperatura e oxigênio no Ribeirão da Onça, em que foi encontrado $r=0,14$. Os autores concluem que essa falta de correlação pode ser efeito das concentrações de material orgânico em suspensão devido intensificação de atividades agrícolas e pecuárias mais próximas às margens $e$, do consequente carreamento da camada superficial do solo para $o$ ribeirão.

Figura 12. Análise de correlação de Pearson do parâmetro de temperatura $\left({ }^{\circ} \mathrm{C}\right)$ da água com o $\mathrm{OD}(\mathrm{a})$ e, entre o $\mathrm{pH}$ com a CE (b) para o rio Paraíso Jataí-GO.

a)

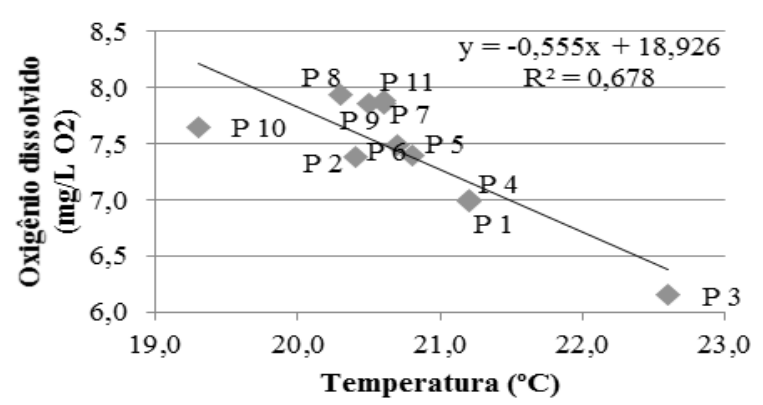

b)

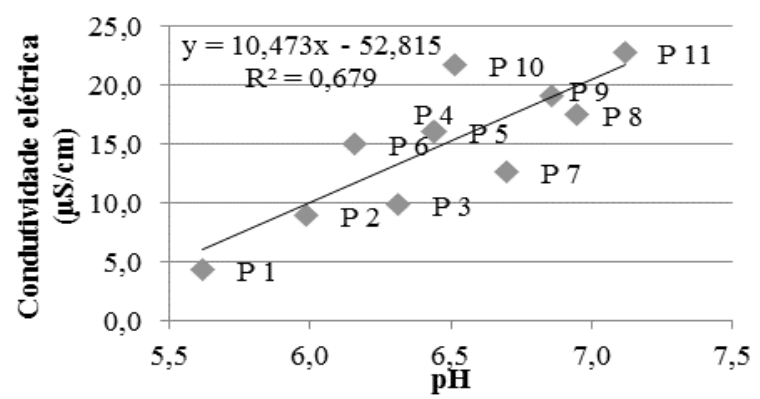

Fonte: Dados da pesquisa (2014). Org. dos autores.

As correlações obtidas entre $\mathrm{opH}$ com a $\mathrm{CE}$ e $\circ \mathrm{NaCl}$ tiveram respostas semelhantes. Observa-se, assim, no período seco, correlações moderadas positivas entre o $\mathrm{pH}$ com a $\mathrm{CE}(\mathrm{r}=0,516)$ e o $\mathrm{NaCl}(\mathrm{r}=0,529)$. No período chuvoso, o $\mathrm{pH}$ teve uma correlação forte positiva com $\mathrm{CE}(r=0,824)$ e com $\circ \mathrm{NaCl}(r=0,845)$. O coeficiente de determinação linear entre o pH e a CE explicaram $68 \%$ e, entre o pH e a $\mathrm{NaCl}$ explicaram $71 \%$ dos dados na linha de dispersão (Figura 12-b e Figura 13a, respectivamente). Isso se justifica, no período chuvoso, com o aumento na concentração de íons em solução aquosa, reflete diretamente nos teores de pH e no aumento da $\mathrm{CE}$ e o $\mathrm{NaCl}$. Essa relação pode estar ligada à carga pontual, como carreamento de sedimentos, lixiviação de nutrientes ou resíduos lançados no meio aquático (NEU et al., 2014). Carvalho et al. (2000) colaboram, afirmando que existe correlação da pluviosidade com a CE da água e que essa pode ser resultado de pouca cobertura vegetal em bacias degrada, favorecendo o aporte de materiais do 
solo para o ambiente aquático, aumentando a concentração de sólidos suspensos e contribuindo para esta relação limnológica.

Figura 13. Análise de correlação de Pearson do parâmetro de pH com o $\mathrm{NaCl}$ (a) e a turbidez (b) para o rio Paraíso Jataí-GO.

a)

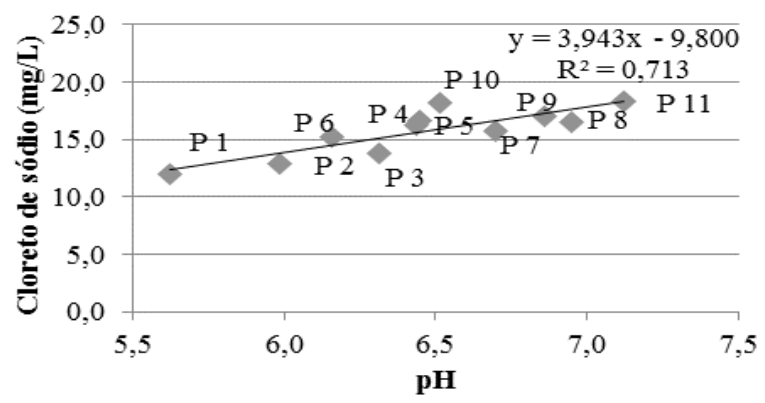

b)

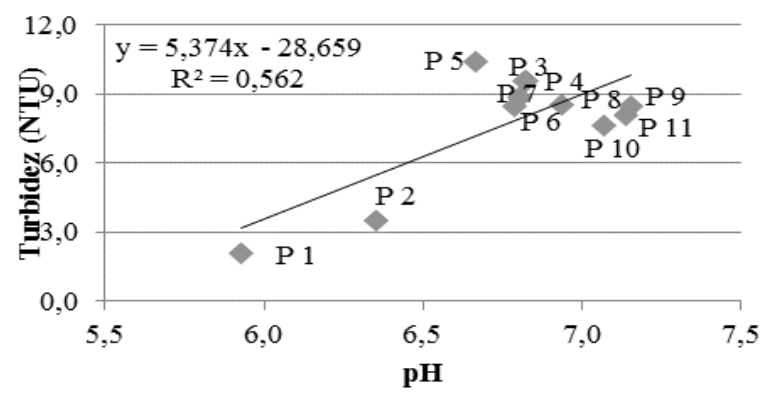

Fonte: Dados da pesquisa (2014). Org. dos autores.

Encontramos, no período seco, para o parâmetro $\mathrm{pH}$, uma correlação moderada positiva com a turbidez, com o valor de $r=0,609$. Observa-se também, no período chuvoso, que o pH teve correlação fraca positiva com o valor de $r=0,372$. A Figura 13-b, demonstra que os dados acompanharam 56\% da linha de dispersão. Essa correlação já foi constada no estudo de autores et al. (2014) para os afluentes do rio Claro, no reservatório da UHE Barra dos Coqueiros-GO, onde obtiveram uma relação de $r=0,87$ para o mês de março/2012, no período chuvoso e concluíram que o aumento ou diminuição do $\mathrm{pH}$ se relaciona com a quantidade e o tipo de material presente na água.

Figura 14. Análise de correlação de Pearson do parâmetro de pH com o OD (a) e a PT (b) para o rio Paraíso Jataí-GO.

a)

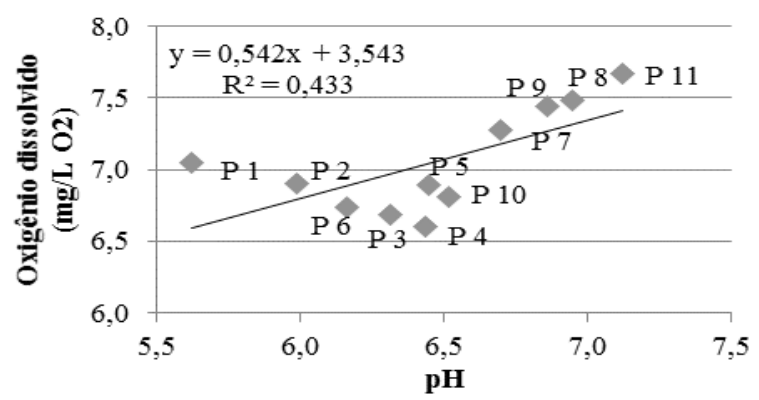

b)

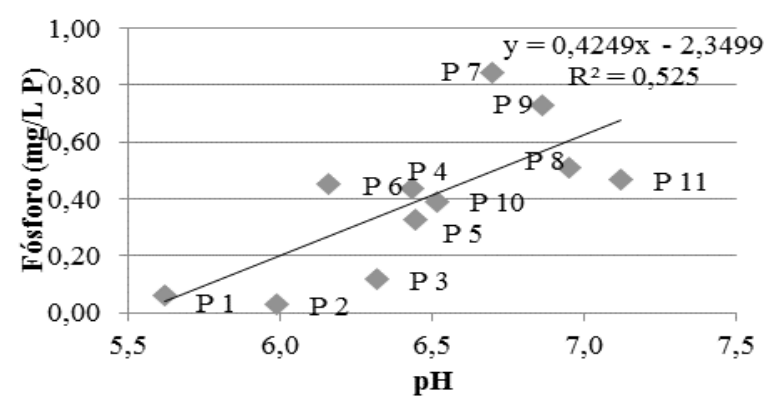

Fonte: Dados da pesquisa (2014). Org. dos autores.

Observou-se, no período seco, entre os parâmetros de $\mathrm{pH}$ e o OD, uma correlação de fraca positiva $(r=0,181)$ e, entre $\circ \mathrm{pH}$ com o PT uma correlação moderada positiva $(r=0,665)$. No período chuvoso, o pH apresentou uma correlação 
moderada positiva com OD $(r=0,658)$ e uma correlação forte positiva $(r=0,725)$ com PT. O coeficiente de determinação $\left(r^{2}\right)$ no período chuvoso, o pH com o parâmetro de OD se mostraram $43 \%$ ajustados com a linha de tendência (Figura 14-a) e para os dados de PT 52\% ajustados (Figura 14-b). Significa que, no período chuvoso, com a atividade agropecuária e à entrada de nutrientes de $\mathrm{N}$ e $\mathrm{P}$ tem-se a elevação do valor de $\mathrm{pH}$. Para o OD, era esperado que seu valor diminuísse devido a entrada de nutrientes ( $N$ e P) (MARTINS, 2009). Porém, a maior vazão nos pontos localizados a jusante do rio elevou os valores de OD.

Verifica-se, na Tabela 3, que, no período seco, não houve concentrações de NT no rio Paraíso. E, no período chuvoso, o pH e OD correlacionaram moderadamente com o NT $(r=0,458)$ (Tabela 3). A entrada de nutrientes no ambiente aquático altera os valores de NT colaborando para uma relação direta com o pH (Figura 15-a).

Figura 15. Análise de correlação de Pearson do parâmetro de pH com a NT (a) e, entre o $\mathrm{CE}$ com a $\mathrm{NaCl}$ (b) para o rio Paraíso Jataí-GO.

a)

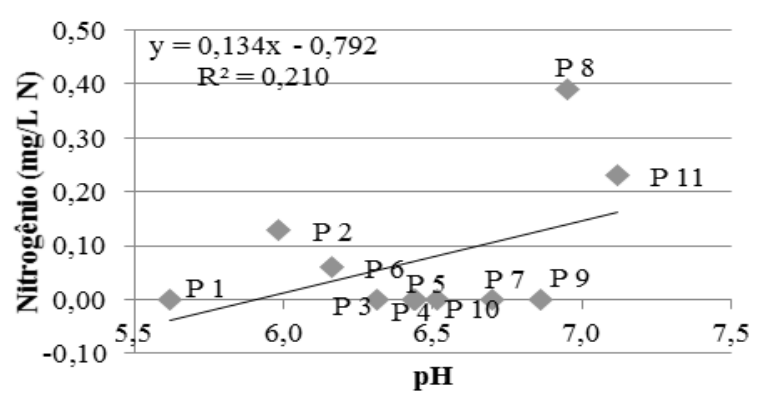

b)

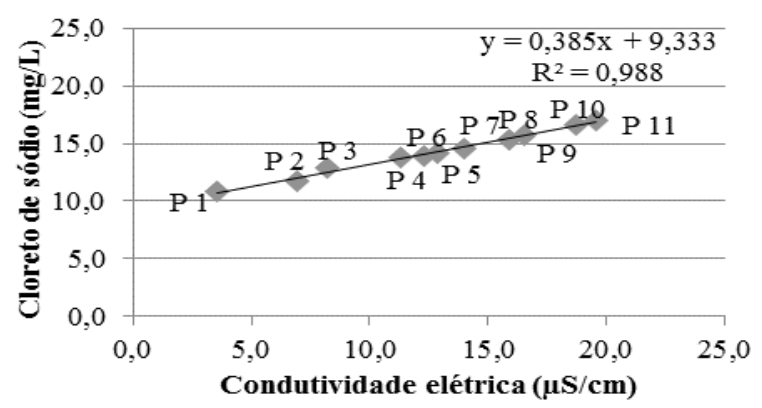

Fonte: Dados da pesquisa (2014). Org. dos autores.

As correlações encontradas entre a $\mathrm{CE}$ e $\mathrm{NaCl}$ foram classificadas como perfeita positiva em ambos os períodos, seco $(r=0,994)$ e chuvoso $(r=0,979)$ (Tabela 3). $O$ coeficiente de determinação linear $\left(r^{2}\right)$ entre a $\mathrm{CE}$ e $\mathrm{O} \mathrm{NaCl}$, no período chuvoso, indicaram 98\% dos dados ajustados à linha de tendência (Figura 15-b). A variabilidade desses parâmetros está associada diretamente à quantidade de sal na água, sendo que a intensificação dos valores dos mesmos é ocasionada no período chuvoso devido à dissolução ou intemperização das rochas e solos, aumentando a concentração de íons no meio aquático (ROCHA et al., 2014).

A CE teve correlações moderada positiva com a turbidez em ambos os períodos, seco $(r=0,574)$ e chuvoso $(r=0,587)$. Houve, também, correlação na escala moderada positiva entre $\circ \mathrm{NaCl}$ e a turbidez com o valor de $r=0,588$ no 
período seco e de $r=0,530$ no período chuvoso (Tabela 3 ). No coeficiente de determinação $\left(r^{2}\right)$ entre a turbidez com a $\mathrm{CE}$ e $\circ \mathrm{NaCl}$, os dados se mostraram ajustados cerca de $34 \%$ para ambos os parâmetros referidos (Figuras 15-a e 15-b). A turbidez se correlacionam com esses parâmetros por ser uma medida da quantidade de partículas suspensa na água (areia, bactérias, fitoplâncton, detritos orgânicos, silte, entre outros), onde as reações químicas e biológicas da água na dissolução desses íons são responsáveis por suas alterações (PINTO, OLIVEIRA e PEREIRA, 2009), dentre esses íons, o $\mathrm{NaCl}$, por exemplo, possui um alto coeficiente de solubilidade.

Figura 15. Análise de correlação de Pearson do parâmetro de turbidez com a CE (a) e o $\mathrm{NaCl}$ (b) para o rio Paraíso Jataí-GO.

a)

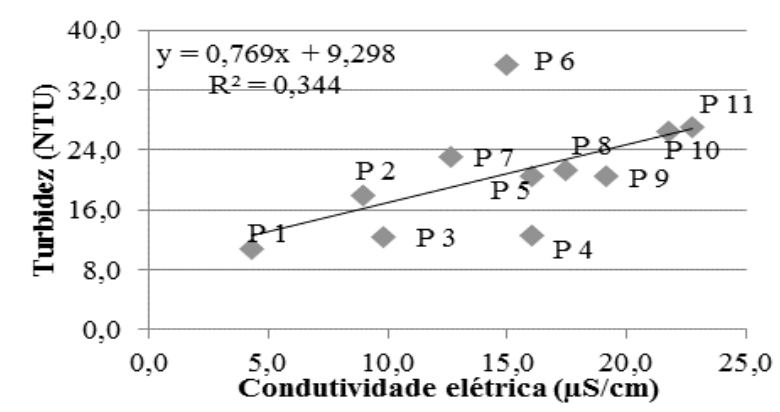

Fonte: Dados da pesquisa (2014). Org. dos autores. b)

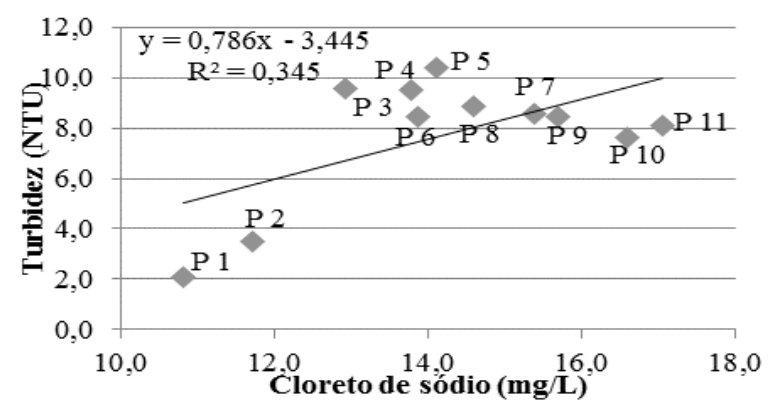

No período seco, Tabela 3, para o parâmetro CE foi encontrada correlação moderada positiva com o OD $(r=0,698)$ e correlação fraca positiva com o PT ( $r=$ 0,252 ). A correlação encontrada, no período chuvoso, da variável CE com OD ( $r=$ $0,366)$ foi fraca positiva e, com o PT $(r=0,577)$ obteve-se uma correlação moderada positiva. O coeficiente de determinação $\left(\mathrm{r}^{2}\right)$ de CE para os dados de OD e PT mostraram ajustados cerca de $49 \%$ e $33 \%$, respectivamente (Figuras 16-a e 16-b). Estes resultados não eram esperados, uma vez que os altos valores de CE influenciariam na diminuição da solubilização do oxigênio da água, que associado com os valores de temperatura aceleraria a conversão dos sólidos em suspensão e nutrientes solúveis (p.ex. fósforo) (SILVA, QUEIROZ e TRIVINHO-STRIXINO, 2008). As mesmas classificações de correlações foram observadas para o $\mathrm{NaCl}$ em relação OD ( $r=0,634$ /período seco; $r=0,369$ /período chuvoso) e PT ( $r=0,311$ /período seco; $r=0,655$ /período chuvoso), com os coeficientes de $r^{2}$ de 0,402 e 0,430, respectivamente (Figuras 17-a e 17-b). A relação entre o $\mathrm{NaCl}$ e $\circ \mathrm{OD}$ deveria ter resultado em uma correlação inversa, pois quanto maior a concentração de sais 
minerais na água, menor é o valor de OD. No entanto, os nossos resultados mostraram que a medida que os afluentes desaguam no rio principal, fazem com que aumente o carreamento de sais minerais na água, e consequentemente com o aumento da vazão, tem-se o aumento do OD, pelo turbilhonamento da água.

Figura 16. Análise de correlação de Pearson do parâmetro de CE com a OD (a) e o PT (b) para o rio Paraíso Jataí-GO.

a)

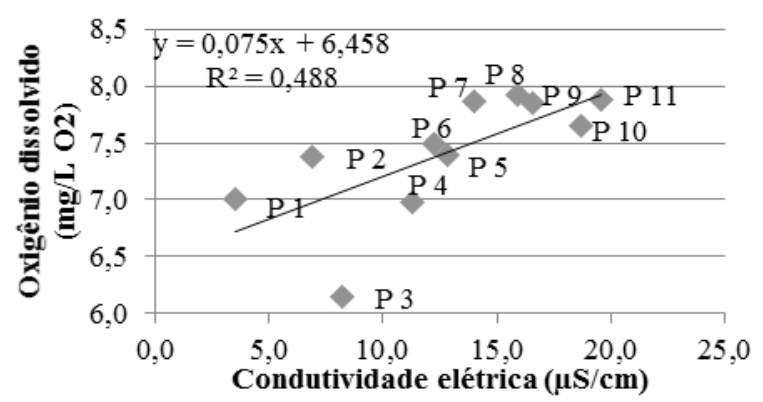

b)

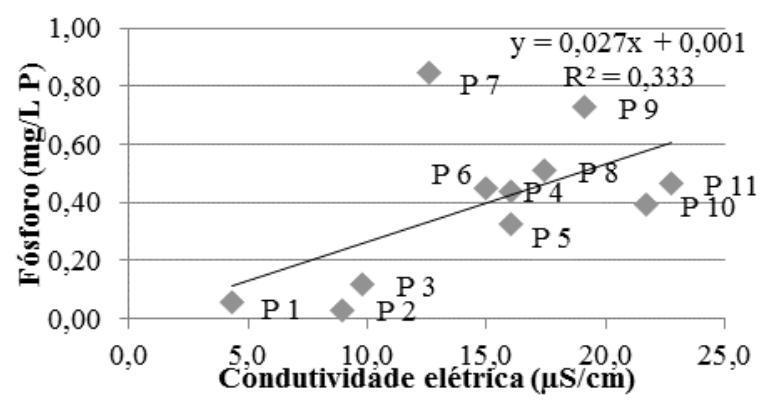

Fonte: Dados da pesquisa (2014). Org. dos autores.

Figura 17. Análise de correlação de Pearson do parâmetro de $\mathrm{NaCl}$ com a OD (a) e o PT (b) para o rio Paraíso Jataí-GO.

a)

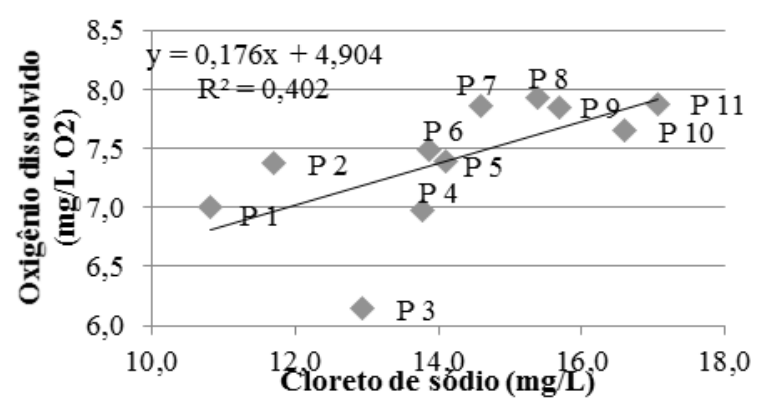

b)

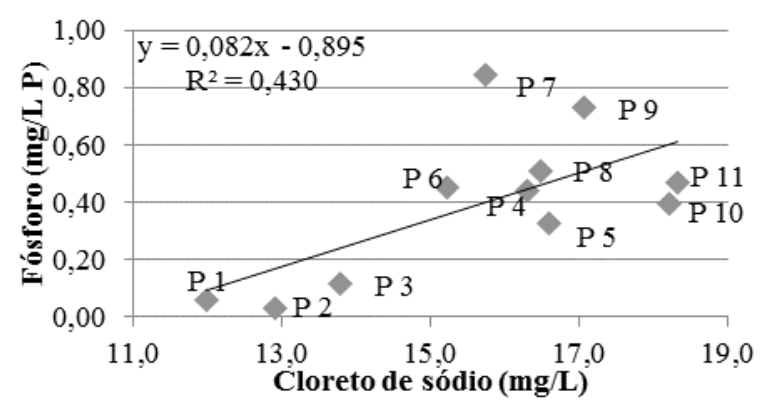

Fonte: Dados da pesquisa (2014). Org. dos autores.

Podemos verificar que a turbidez teve correlação moderada positiva com os CT com o valor de $r=0,483$ no período seco e correlação de fraca negativa com o valor de $r=-0,346$ no período chuvoso, indicando que no período seco devido à pouca vazão da água, favoreça a proliferação de bactérias em suspensão na água, influenciando nos altos valores de turbidez e, enquanto que no período chuvoso, existe o aumento do carreamento dos organismos aquáticos (drift), devido o aumento da velocidade e da vazão da água (BISPO et al., 2001). Entre a turbidez e o PT, houve correlação fraca positiva no período seco $(r=0,367)$ e uma correlação moderada positiva no período chuvoso $(r=0,457)$. No período chuvoso, tal fato pode ser explicado, devido ao início das atividades agrícolas, onde o uso de defensivos e 
fertilizantes agrícolas, quando removidos dos solos pelas chuvas para os corpos hídricos, faz com que os sedimentos em suspensão (turbidez) sejam ricos em PT (BRITO et al., 2005). No coeficiente de determinação $\left(r^{2}\right)$ entre a turbidez e a CT, $23 \%$ dos dados está ajustada a linha de tendência e, entre a turbidez e o PT, $21 \%$ dos dados estão ajustados à linha de tendência (Figuras 18-a e 18b).

Figura 18. Análise de correlação de Pearson do parâmetro de turbidez com os CT (a) e o PT (b) para o rio Paraíso Jataí-GO.

a)

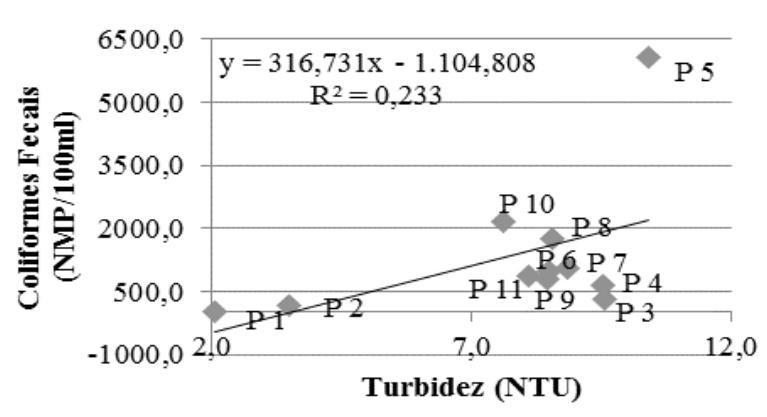

b)

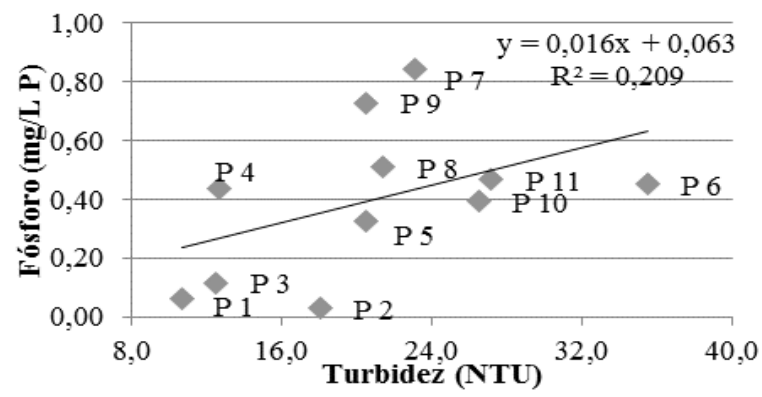

Fonte: Dados da pesquisa (2014). Org. dos autores.

De acordo com a Tabela 3, foi encontrada correlação fraca negativa entre OD e PT, com o valor de $r=-0,125$ no período seco, e fraca positiva com o valor de $r=0,492$ no período chuvoso. Houve, também, entre o OD e o NT uma correlação moderada positiva com o valor de $r=0,583$ no período chuvoso. $O$ aumento ou diminuição de PT e NT se relaciona com as concentrações de OD. A literatura científica descreve que, com as práticas agrícolas e o lançamento de efluentes residuais, têm-se o aumento na carga de nutrientes de PT e NT, que consequentemente, influenciam na queda nos níveis de oxigênio (TOMANOVA, MOYA e OBERDORFF, 2008), no entanto não foi detectado, uma vez que era esperado que OD tivesse uma correlação inversa a esses parâmetros.

Figura 19. Análise de correlação de Pearson do parâmetro de OD com a PT (a) e o NT (b) para o rio Paraíso Jataí-GO.

a)

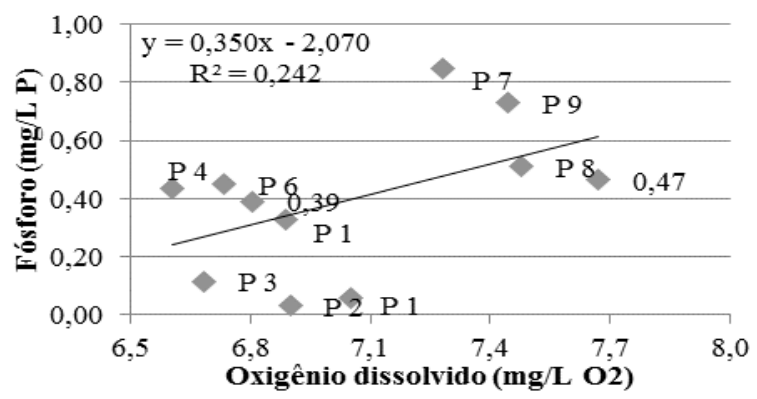

b)

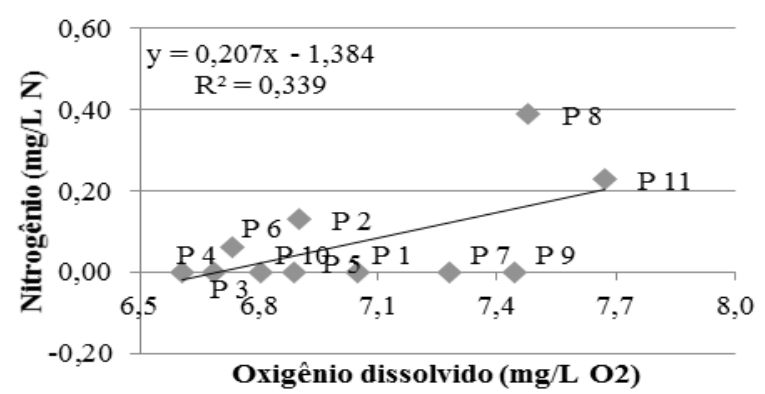

Fonte: Dados da pesquisa (2014). Org. dos autores. 


\section{Considerações Finais}

Avaliaram-se, neste trabalho, parâmetros físico-químicos de qualidade da água, de maneira espacial e temporal. E, estudou-se a relação entre os resultados encontrados para esses parâmetros através da correlação de Pearson, visando verificar os padrões e criar indicadores da integridade ambiental sob ótica de uso e ocupação do solo da bacia do rio Paraíso-Jataí-GO.

Dos resultados encontrados, apenas os pontos 1 e 2 não apresentaram inadequabilidade em relação aos parâmetros CT e PT. Esses pontos estão localizados na nascente do rio Paraíso e possuem a vegetação nativa preservada. Nos demais trechos amostrais, os resultados encontrados para os parâmetros CT e PT, estão enquadrados na classe III da Resolução CONAMA n 357/05 (BRASIL, 2005).

As melhores correlações das medidas limnológicas foram encontradas para os parâmetros de temperatura da água e OD; entre os parâmetros de pH e PT, e entre os parâmetros que se relacionam diretamente com a quantidade de íons presentes na água $\mathrm{pH}, \mathrm{CE}$ e $\mathrm{NaCl}$. Os maiores valores de correlação verificados para $\mathrm{pH}$ e $\mathrm{CE} ; \mathrm{pH}$ e NaCl ; $\mathrm{pH}$ e PT, ocorreram no período de maior intensidade de chuva na bacia, o que aumenta a concentração de íons nos rios pelo carreamento de material e dissolução ou intemperização das rochas e solos da região e, agravadas pelas atividades antrópicas no entorno.

Os parâmetros de temperatura da água e OD se correlacionaram, no período seco, devido aos processos químicos de decomposição do material orgânico na água e, que diminuem ou aumentam de acordo com a temperatura.

Por fim, por meio da análise espacial e temporal dos dados, é possível observar que as variações estão relacionadas ao tipo do uso da terra da bacia e aos fatores litológicos, principalmente, àqueles influenciados pela Formação Vale do Rio do Peixe, que é rico em material carbonático. Além disso, observa-se também que a precipitação na área da bacia influência nas variações dos resultados encontrados para estes parâmetros.

\section{REFERÊNCIAS}

AMERICAN PUBLIC HEALTH ASSOCIATION (APHA) -AWWA; WEF. Standard Methods for the Examination of Water and Wastewater. 20. ed. Washington, 1998, 1085p. 
BISPO, P. D. C.; OLIVEIRA, L. G.; CRISCI, V. L.; SILVA, M. M. A pluviosidade como fator de alteração da entomofauna bentônica (Ephemeroptera, Plecoptera e Trichoptera) em córregos do Planalto Central do Brasil. Acta Limnologica Brasiliensia, v. 13, n. 2, p. 1-9, 2001.

BRASIL. Conselho Nacional do Meio Ambiente. Resolução CONAMA n 357, de 17 de março de 2005. Brasília-DF, 2005.

BRITO, L. T. L.; SRINIVASAN, V. S.; SILVA, A. S.; GHEYI, H. R.; GALVÃO, C.O.; HERMES, L. C. Influência das atividades antrópicas na qualidade das águas da bacia hidrográfica do Rio Salitre. Revista Brasileira de Engenharia Agrícola e Ambiental, Campina Grande-PB, v.9, n.4, p.596-602, 2005.

CARVALHO, A. R.; SCHLITTLER, F. H. M.; TORNISIELO, V. L. Relações da atividade agropecuária com parâmetros físicos químicos da água. Química Nova, São Paulo-SP, v.23, n.5, p. $618-622,2000$.

COLUNA, N. M. E. Análise temporal e espacial da qualidade da água na bacia hidrográfica do Zerede, Timóteo - MG. In: I Seminário de Recursos Hídricos da Bacia Hidrográfica do Paraíba do Sul: o Eucalipto e o Ciclo Hidrológico. Taubaté, Brasil; p. 207-214, 2007.

HAVEN, P. H.; EVERT, R. F.; EICHHORN, S. E. Biologia Vegetal. Rio de Janeiro: Editora Guanabara Koogan, 2001.

IBGE - Instituto Brasileiro de Geografia e Estatística. Cartas topográficas na escala de 1:50.000. Rio de Janeiro, 1978.

LIMA, A. M.; MARIANO, Z. F. Análise microclimática no interior e fora das florestas estacionais semideciduais na área da bacia da usina hidrelétrica de Caçu-GO. Revista do Departamento de Geografia - USP, São Paulo-SP, v. 27, p. 67-87, 2014.

MARTINS, A. S. Avaliação das águas superficiais sob uso e ocupação na sub - bacia do rio Candeias/RO-Amazônia ocidental. Mestrado do Programa de Pós-Graduação em Desenvolvimento Regional e Meio ambiente. Porto Velho-RO, 2009, 124p.

NASCIMENTO, J. M.; GALASTRI, N. A.; ALMEIDA, T. L. A Importância das Análises Limnológicas para Avaliação de Impactos nos Recursos Hídricos: Córrego Água Fria, São Carlos-SP. In: 4 Simpósio de Tecnologia em Meio Ambiente e Recursos Hídricos. Editora RIMA, São Carlos-SP, v. 1, p. 1-13, 2012.

NEU, D. H.; BOSCOLO, W. R.; DIEMER, O.; CAMARGO, D. J.; WÄCHTER, N.; FEIDEN, A. Qualidade da Água em um Reservatório Neotropical Associado à Criação de Peixes em Tanques Rede: Reservatório de Itaipu. Revista Agrarian, Dourados-MS, v.7, n.23, p.139146, 2014.

PINTO, A. L.; OLIVEIRA, G. H.; PEREIRA, G. A. Avaliação da eficiência da utilização do oxigênio dissolvido como principal indicador da qualidade das águas superficiais da Bacia do Córrego Bom Jardim, Brasilândia/MS. In: Anais II Seminário de Recursos Hídricos da Bacia Hidrográfica do Paraíba do Sul: Recuperação de Áreas Degradadas Serviços Ambientais e Sustentabilidade. Taubaté-SP, Brasil, IPABHi, p. 553-560, 2009.

RESENDE, A.V. de. Agricultura e qualidade da água: contaminação da água por nitrato. Brasília: EMBRAPA Cerrados, D.57, 2002. 29p.

ROCHA, H. M.; CABRAL, J. B. P.; BRAGA, C. C. Avaliação Espaço-Temporal das Águas dos Afluentes do Reservatório da UHE Barra dos Coqueiros/Goiás. Revista Brasileira de Recursos Hídricos, v. 19, n. 1, p. 131-142, 2014. 
SANTOS, C. Estatística Descritiva-manual de autoaprendizagem. Lisboa: Edições Sílabo, 2007.

SIEG - Sistema Estadual de Estatística e de Informações Geográficas de Goiás. Disponível em: http://www.sieg.go.gov.br/; Acesso em: 25/11/2014.

SANO, S. M.; ALMEIDA, S. P.; RIBEIRO, J. F. Cerrado: ecologia e flora. Brasília (DF): Embrapa Cerrados. Embrapa Informação Tecnológica, v. 2, 2008. 1.279 p.

SILVA, A. M. M.; SACOMANI, L. B. Tehnical note usingchemica land physical parameters to define the quality of Pardo river water (Botucatu-SP-brazil). Wat. Res. V. 35, n.6, p. 16091616, 2001.

SILVA, M. S. G. M.; QUEIROZ, J. F.; TRIVINHO-STRIXINO, S. Indicadores biológicos de qualidade. In: QUEIROZ, J. F.; SILVA, M. S. G. M.; TRIVINHO-STRIXINO, S. Organismos Bentônicos: biomonitoramento da qualidade de água. Jaguariúna: Embrapa Meio Ambiente, v. 1, p. 26-35, 2008.

YAMAGUCHI, M. U; CORTEZ, L. E. R; OTTONI, L. C. C; OYMA, J. Qualidade microbiológica da água para consumo humano em instituição de ensino de Maringá-PR. O Mundo da Saúde, São Paulo-SP, v. 37, n. 3, p. 312-320, 2013.

ZILLMER, T. A.; VARELLA, R. F.; ROSSETE, A. A. Avaliação de algumas características físico-quimicas da água do ribeirão Salgadinho, Nova Xavantina-MT. In: Holos Environment. v.7, n.2, 2007. 125p.

TOMANOVA, S.; MOYA, N.; OBERDORFF, T. Using macroinvertebrate biological traits for assessing biotic integrity of neotropical streams. River Research and Applications, v. 24, n. 9, p. 1230-1239, 2008.

\section{NOTAS DE AUTOR}

\section{CONTRIBUIÇÃO DE AUTORIA}

Hudson Moraes Rocha - Concepção, coleta de dados, análise de dados, elaboração do manuscrito, participação na discussão dos resultados, revisão da versão final do trabalho.

João Batista Pereira Cabral - Concepção, delineamento metodológico, coleta de dados, participação na discussão dos resultados, revisão da versão final do trabalho.

Daiane Ferreira Batista - Coleta de dados, análise de dados, participação na discussão dos resultados.

Leandro Gonçalves Oliveira - Delineamento metodológico, planejamento das atividades de pesquisa, aplicação de técnicas estatísticas.

\section{FINANCIAMENTO}

O presente trabalho foi realizado com apoio da Coordenação de Aperfeiçoamento de Pessoal de Nível Superior Brasil (CAPES) - Código de Financiamento 001.

\section{CONSENTIMENTO DE USO DE IMAGEM}

Não se aplica.

\section{APROVAÇÃO DE COMITÊ DE ÉTICA EM PESQUISA \\ Não se aplica.}

\section{CONFLITO DE INTERESSES}

Não se aplica.

\section{LICENÇA DE USO}

Este artigo está licenciado sob a Licença Creative Commons CC-BY. Com essa licença você pode compartilhar, adaptar, criar para qualquer fim, desde que atribua a autoria da obra. 
ROCHA H. M, CABRAL J. B. P, BATISTA D. F, OLIVEIRA L. G

HISTÓRICO

Recebido em: 15-08-2016

Aprovado em: 23-01-2019 